\title{
Centro de Biologia Marinha
}

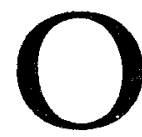

Centro de Biologia Marinha da Universidade de São Paulo surgiu em 1954, como Laboratório de Biologia Marinha, administrado por uma fundação. Desta faziam parte professores da Faculdade de Filosofia, Ciências e Letras (Departamentos de Fisiologia, Zoologia, Botânica e Biologia) e pesquisadores de outras instituiçóes. Em 1962, foi incorporado à USP, sob a denominaçáo de Instituto de Biologia Marinha, sendo, em 1980, transformado no Centro de Biologia Marinha, (CEBIMar), que tem o status atual de Instituto Especializado.

Os pequisadores vinculados ao CEBIMar desenvolvem trabalhos nas mais diversas áreas da Biologia e da Oceanografia. Entre elas, levantamentos faunísticos e florísticos, efeitos farmacológicos de toxinas naturais, influência de poluentes, variação espaço-temporal das comunidades planctônicas e bentônicas etc. No momento, estáo sendo realizados com a colaboraçáo do CEBIMar, cerca de $\mathbf{8 0}$ projetos de pesquisa, vários deles com a participação de professores estrangeiros. Estes estudos, além de seu valor teórico, constituem importante subsídio para pesquisas de cunho aplicado, como manejo ambiental, criação de organismos, entre outros.

Oferece ainda a infra-estrutura necessária para disciplinas de graduação e pós-graduação da USP, Unesp, Unicamp e outras instituiçōes. $\mathrm{Na}$ extensáo de serviços à comunidade, o CEBIMar desenvolve trabalho de educação ambiental e divulgação científica, recebendo a visitação do público em geral e oferecendo programas especiais para crianças durante as férias.

CEBIMar (Centro de Biologia Marinha), Instituto Especializado, USP, Praia do Segredo, São Sebastiăo - SP. 